\title{
STRUCTURE AND MECHANICAL PROPERTIES OF HIGH-ALLOY MANGANESE - ALUMINUM STEELS
}

\author{
J. Charles, A. Berghézan and A. Lutts \\ Université Catholique de Louvain, ESA/MEPH, Place Sainte Barbe, 2, \\ 1348 Louvain La Neuve, Betgium
}

(Accepted 9 August 1982)

SUMMARY.

The development of industrial applications of superconducting magnets in such fields as nuclear fusion reactor and levitation railways requires non-magnetic structural materials characterized by high strength and toughness at cryogenic temperatures. In this cases, the classical $\mathrm{Fe}-\mathrm{Ni}-\mathrm{Cr}$ austenitic alloys (AISI 300 serie) due to their microstructural instability during plastic deformation at low temperature and their relative poor yield strength do not present all the expected requirements.

For this reasons, the Fe-Mn base alloys have been the object of increasing interest. These high manganese (20-35\%) non magnetic austenitic steels stabilized and strengthened by moderate chromium $(5-10 \%)$ and relative high carbon $(0,2-0,6 \%)$ additions can be considered as potential substitutes for $\mathrm{Fe}-\mathrm{Ni}$-Cr steels in regards to their low cost, low coefficient of thermal expansion under the Neel temperature and high strength and toughness for cryogenic uses.

Dur present study concerns first, the influence of $5 \% \mathrm{Al}$ additions on the structure and mechanical properties of the $F e-(23-30)$ Mn alloys and, second, the strengthening solid solution effect of carbon and silicon additions to the Fe-Mn-Al austonitic alloys.

Mechanical properties under uniaxial loading at room temperature and $-196 \mathrm{C}$, Charpy $V$-notch impacts at $-196 \mathrm{C}$ and $\mathrm{HV}_{50}$ hardness measurements have been performed.

These results are discussed on basis of optical metallographic, scanning and transmission electron examinations. Complementary studies on thermal conductivity have also been performed.

The main conclusions can been summarised as follow :

1) Role of aluminum additions (5\%Al)

- suppression of the $Y \rightarrow \varepsilon$ martensitic transformation which occurs in the $\mathrm{Fe}-(23-30) \mathrm{Mn}$ alloys.

- strengthening of the austenite by solid solution hardening (50 MPa/5\% AI)

- more than 6 Al added : formation of ferrite grains.

- decrease of thermal conductivity $(0,09 \mathrm{~W} / \mathrm{cm} \mathrm{K}$ at -1960 with $5 \% \mathrm{Al})$

2) Role of carbon additions :

- strengthening by solid solution hardening (160 MPa / $0,5 \% \mathrm{C}$ ]

- moderate decrease of Charpy $V$-notch value

- austenite stabilization effect.

$3)$ Role of silicon additions :

- strengthening by solid solution hardening (100 MPa / $2 \% \mathrm{Si}$ )

- decrease of Charpy $V$-notch values.

- ferrite stabilization effect.

The Fe-Mn-AI-C austenitic alloys by their increased room temperature 0,2 yield strength (350 MPa) and good charpy $V$-notch $v a l u e s\left\{\geqslant 130 J / \mathrm{cm}^{2}\right.$ ) at $-196 \mathrm{C}$ present mechanical properties which renders them potential candidates for the substitution of Fe-Ni-Cr austenitic støls in such fields as cryogenic applications.

Furthermore, these new grades do not depend on possible scarcity of nickel or chromium resources. 